\title{
Works of Professor Masatsugu Tsuji
}

\section{Books}

1. 集合論 (共立出版), 1933

2. 複素変数函数論 (共立出版), 1934

3. 調和函数論 (岩波書店), 1934

4. 多複素变数函数論 (岩波書店), 1935

5. 解析雑論 (共立出版), 1935

6. 高等微分積分学 I (共立出版), 1950

7. 現代の数学 (共立出版), 1950 (弥永昌吉と共編)

8. 実变数函数論 (清水書院), 1950

9. 高等数学通論 I, II. (共立出版), 1951 (田中明雄と共著)

10. 高等数学演習 (共立出版), 1952 (田中明雄と共著)

11. 函数論 上, 下 (朝倉書店), 1952

12. Potential theory in modern function theory (Maruzen Publ. Co.), 1959

13. 大学演習函数論 (裳華房), 1959 (小松勇作と共編)

14. 新三角法 (共立出版), 1959 (平野智治と共著)

\section{Papers}

1. On the distribution of the zero points of sections of a power series. Jap. J. Math. 1 (1924), 109-140.

2. On the distribution of the zero points of sections of a power series, II. Jap. J. Math. 2 (1925), 147-154.

3. On the distribution of the zero points of sections of a power series, III. Jap. J. Math. 3 (1926), 49-52.

4. On Blaschke's theorem. Jap. J. Math. 3 (1926), 65-68.

5. On a power series which has only algebraic singularities on its convergence circle. Jap. J. Math. 3 (1926), 69-85.

6. On the zero points of a bounded analytic function. Proc. Imp. Acad. Tokyo 2 (1926), $245-248$.

7. On a generalization of Picard's theorem. Proc. Imp. Acad. Tokyo 2 (1926), 364-365.

8. On a power series which has only algebraic singularities on its convergence circle, II. Jap. J. Math. 4 (1927), 49-56.

9. On an extension of the theorem of Vivanti-Dienes. Jap. J. Math. 4 (1927), 125-127.

10. On a power series which has only algebraic singularities on its convergence circle, III. Jap. J. Math. 4 (1927), 129-139.

11. On a power series which has only algebraic singularities on its convergence circle, IV. Jap. J. Math. 5 (1928), 163-184.

12. On the distribution of the zero points of sections of a power series, IV. Jap. J. Math. 6 (1929), 245-249.

13. On the roots of the characteristic equation of a certain matrix. Proc. Imp. Acad. Tokyo 5 (1929), 111-112.

14. On the theorems of Carathéorody and Lindelöf in the theory of conformal representation. Jap. J. Math. 7 (1930), 91-99.

15. Theorems concerning Poisson integrals. Jap. J. Math. 7 (1930), 227-253.

16. On analytical transformations of a Reinhardt's domain into itself. Jap. J. Math. 9 (1932), 219-226. 
17. On Fatou's theorems on Poisson integrals. Jap. J. Math. 15 (1938), 13-18.

18. On the limits of indetermination of bounded harmonic functions. Jap. J. Math. 15 (1938), 19-26.

19. On the theorems of Valiron and Milloux. Jap. J. Math. 15 (1938), 255-267.

20. On a positive harmonic function in a half-plane. Jap. J. Math. 15 (1938), 277-285.

21. (with S. Kakeya) On the mesure of section of the integral curves. Jap. J. Math. 16 (1939), 71-78.

22. On Lindelöf's theorem in the theory of differential equations. Jap. J. Math. 16 (1939), 149-161.

23. On the determination of the singular point of the half-line through the center of the convergence circle. Jap. J. Math. 16 (1939), 393-306.

24. 解析函数ノ集積值ニッイテ, 高数研究 8 (1939), 1-4.

25. A theorem on conformal representation. Jap. J. Math. 17 (1940), 97-108.

26. On the behaviour of an inverse function of a meromorphic function at its transcendental singular point. Proc. Imp. Acad. Tokyo 17 (1941), 414-417.

27. On the behaviour of an inverse function of a meromorphic function at its transcendental singular point, II. Proc. Imp. Acad. Tokyo 17 (1941), 474-475.

28. On Tonelli's theorems on a sequence of rectfiable curves. Jap. J. Math. 17 (1941), 401-410.

29. On the Green's function. Jap. J. Math. 18 (1942), 1-5.

30. On the behaviour of an inverse function of a meromorphic function at its trancendental singular point, III. Proc. Imp. Acad. Tokyo 18 (1942), 132-139.

31. On an extension of Bloch's theorem. Proc. Imp. Acad. Tokyo 18 (1942), 170-171.

32. On a theorem of F. and M. Riesz. Proc. Imp. Acad. Tokyo 18 (1942), 172-175.

33. On Green's lemma. Proc. Imp. Acad. Tokyo 18 (1942), 176-178.

34. On the behaviour of a mermorphic function in the neighbourhood of a closed set of capacity zero. Proc. Imp. Acad. Tokyo 18 (1942), 213-219.

35. On an extension of Löwner's theorem. Proc. Imp. Acad. Imp. Tokyo 18 (1942), 220221.

36. On the zeros of the Riemann zeta-function. Proc. Imp. Acad. Tokyo 18 (1942), 631634.

37. On the cluster set of a mermorpnic function. Proc. Imp. Acad. Tokyo 19 (1943), $60-65$.

38. On the uniform distribution of values of a function mod. 1. Proc. Imp. Acad. Tokyo 19 (1943), 66-69.

39. Some metrical theorems on a set of points. Proc. Imp. Acad. Tokyo 19 (1943), $110-113$.

40. On the domain of existence of an implicit function defined by an integral relation $G(x, y)=0$. Proc. Imp. Acad. Tokyo 19 (1943), 235-240.

41. On the Riemann surface of an inverse function of a meromorphic function in the neighbourhood of a closed set of capacity zero. Proc. Imp. Acad. Tokyo 19 (1943), $257-258$.

42. On non-prolongable Riemann surfaces. Proc. Imp. Acad. Tokyo 19 (1943), 429-430.

43. Nevanlinna's fundamental theorems and Ahlfors' theorem on the number of asymptotic values. Jap. J. Math 18 (1943), 675-707.

44. Theory of conformal mapping of a multiply connected domain. Jap. J. Math. 18 (1943), 759-775.

45. Theory of conformal mapping of a multiply connected domain, II. Jap. J. Math. 18 (1943), 977-984.

46. Theory of meromorphic functions in a neighbourhood of a closed set of capacity zero. Jap. J. Math. 19 (1944), 139-154.

47. Theory of conformal mapping of a multiply connected domain, III. Jap. J. Math. 
19 (1944), 155-188.

48. On conformal mapping of an infinitely multiply connected domain. Proc. Imp. Acad. Tokyo 20 (1944), 3-6.

49. On Hopf's ergodic theorem. Proc. Imp. Acad. Tokyo 20 (1944), 640-647.

50. On the boundary value of a harmonic function in space. Jap. J. Math. 20 (1944), 113-137.

51. Some metrical theorems on Fuschsian groups. Proc. Imp. Acad, Tokyo 21 (1945), 104-109.

52. On the boundary value of a bounded analytic function of several complex variables. Proc. Imp. Acad. Tokyo 21 (1945), 308-312.

53. Algebraic equations whose roots lie in a unit circle or in a half-plane. Proc. Imp. Acad. Tokyo 21 (1945), 313-320.

54. On a regular function, whose real part is positive in a unit circle. Proc. Imp. Acad. Tokyo 21 (1945), 321-329.

55. On Hopf's ergodic theorem. Jap. J. Math. 19 (1945), 259-284.

56. 単位円内又は半平面内に根它有する代数方程式に就て. 理学 1 (1946), 8-13.

57. On Löwner's differential equation in the theory of univalent functions. Jap. J. Math. 19 (1947), 321-341.

58. Some metrical theorems on Fuchsian groups. Jap. J. Math. 19 (1947), 483-516.

59. On the integral representation of unitary and self-adjoint operator in Hilbert space. Jap. J. Math. 19 (1948), 287-297.

60. On the Green's function associated with a Fuchsian group. Jap. J. Math. 19 (1948), 371-382.

61. On a system of total differential equations. Jap. J. Math. 19 (1948), 383-393.

62. On Blichfeldt's theorem in the geometry of numbers. Jap. J. Math. 19 (1948), 427-431.

63. A remark on Schottky's theorem. J. Math. Soc. Japan 1 (1949), 266-269.

64. Wiman's theorem on integral function of order $<1 / 2$. Proc. Japan. Acad. 26 (1950), 117-130.

65. On Borel's directions of meromorphic functions of finite order. Tôhoku Math. J. 2 (1950), 97-112.

66. Beurling's theorem on exceptional sets. Tôhoku Math. J. 2 (1950), 113-125.

67. On positive definite sequences and functions. Tôhoku Math. J. 2 (1950), 142-165.

68. Some metrical theorems on Fuchsian groups. Kōdai Math. Sem. Rep. 2 (1950), 89-93.

69. On Borel's directions of meromorphic functions of finite order, II. Kōdai Math. Sem. Rep. 2 (1950), 96-100.

70. On Borel's directions of meromorphic functions of finite order, III. Kōdai Math. Sem. Rep. 2 (1950), 104-108.

71. Change of variables in the multiple Lebesgue integrals. J. Math. Soc. Japan 2 (1950), $48-56$.

72. On removale singularities of an analytic function of several complex variables. Jap. J. Math. 20 (1950), 282-286.

73. On meromorphic functions with essential singularities of logarithmic capacity zero. Tôhoku Math. J. 3 (1951), 1-6.

74. A deformation theorem on conformal mapping. Tôhoku Math. J. 3 (1951), 7-12.

75. A theorem on the majoration of harmonic mesure and its applications. Tôhoku Math. J. 3 (1951), 13-23.

76. On a regular function, which is of constant absolute value on the boundary of on an infinite domain. Tôhoku Math. J. 3 (1951), 24-38.

77. On the uniformization of an algebraic function of genus $p \geqq 2$. Tôhoku Math. J. 3 (1951), 277-281.

78. On the order of the derivative of a meromorphic function. Tôhoku Math. J. 3 (1951), 282-284.

79. On Baire's theorem concerning a function $f(x, y)$, which is continuous with 
to each variable $x$ and $y$. J. Math. Soc. Japan 2 (1951), 210-212.

80. A deformation theorem on conformal mapping. J. Math. Soc. Japan 2 (1951), 213215.

81. Some theorems on open Riemann surfaces. Nagoya Math. J. 3 (1951), 141-145.

82. Theory of Fuchsian groups. Jap. J. Math. 21 (1951), 1-27.

83. On the compactness of space $L^{p}(p>0)$ and its application to integral equations. Ködai Math. Sem. Rep. 3 (1951), 33-36.

84. A theorem of Bloch type concerning the Riemann surface of an algebraic function of genus $p>0$. Kōdai Math. Sem. Rep. 3 (1951), 77-78.

85. On the remainder term of Nevanlinna's second fundamental theorem. J. Math. Soc. Japan 4 (1952), 31-36.

86. Existence of a potential function with a prescribed singularity on any Riemann surface. Tôhoku Math. J. 4 (1952), 54-68.

87. Maximal continuation of a Riemann surface. Kōdai Math. Sem. Rep. 4 (1952), 55-56.

88. On F. Riesz' fundamental theorem on subharmonic functions. Tôhoku Math. J. 4 (1952), 131-140.

89. An extension of Bloch's theorem and its applications to normal family. Tôhoku Math. J. 4 (1952), 203-205.

90. Fundamental theorems in potential theory. J. Math. Soc. Japan 4 (1952). 70-95.

91. Theorems in the geometry of numbers for Fuchsian groups. J. Math. Soc. Japan 4 (1952), 189-193.

92. Myrberg's approximation theorem on Fuchsian groups. J. Math. Soc. Japan 4 (1952), 310-312.

93. On the uniform distribution of numbers mod. 1. J. Math. Soc. Japan 4 (1952), 313322.

94. On direct transcendental singularity of an inverse function of a meromorphic function. J. Math. Soc. Japan 5. (1953), 75-80.

95. On the converse of Abel's theorem. J. Math. Soc Japan. 5 (1953), 81-85.

96. On Ahlfors' theorem on covering surfaces. J. Fac. Sci. Univ. Tokyo 6 (1953), 319328.

97. On an integral equation with a kernel $K(x, y) \in L^{p}(1<p \leqq 2)$. Jap. J. Math. 23 (1953), $1-14$.

98. On Dirichlet- and Neumann-problem with integrable boundary values. Jap. J. Math. 23 (1953), 15-37.

99. Theory of meromorphic functions on an open Riemann surfpce with null boundary. Nagoya Math. J. 6 (1953), 137-150.

100. On covering surfaces of a closed Riemann surface of genus $p \geqq 2$. Tôhoku Math. J. 5 (1953). 185-188.

101. On the capacity of general Cantor sets. J. Math. Soc. Japan 5 (1953), 235-252.

102. On lattice points in an $n$-dimensional ellipsoid. J. Math. Soc. Japan 5 (1953), 295-306.

103. On criteria for the regularity of Dilichlet problem. J. Math. Soc. Japan 5 (1953). 321-344.

104. On the exceptional set of a certain harmonic function in a unit sphere. J. Math Soc. Japan 5 (1953), 307-320.

105. A remark on Rengel's theorem concerning Szegö's conjecture. Kōdai Math. Sem. Rep. 5 (1953), 117-118.

106. On Royden's theorem on a covering surface of a closed Riemann surface. J. Math. Soc. Japan 6 (1954), 32-36.

107. A metrical theorem on the singular set of a linear group of Schottky type. J. Math. Soc. Japan 6 (1954), 115-121.

108. On Neumann's problem for a domain on a closed Riemann surface. J. Math. Soc. Japan 6 (1954), 122-128. 
109. The boundary distortion or conformal mapping. J. Math. Soc. Japan 6 (1954). 235261.

110. On the radial order of a certain regular function in a unit circle. J. Math. Soc. Japan 6 (1954), 336-342.

111. On the modulus of a ring domain. Comm. Math. Univ. St. Paul 4 (1955), 1-3.

112. On the cluster set of a meromorphic function. Comm. Math. Univ. St. Paul 4 (1955), 5-9.

113. Remark on my former paper "On an extension of Löwner's theorem". Comm. Math. Univ. St. Paul 4 (1955), 109-110.

114. A metrical theorem on conformal mapping. Comm. Math. Univ. St. Paul 4 (1955), $111-112$.

115. A remark on my former paper "Theory of Fuchsian groups". Comm. Math. Univ. St. Paul. 4 (1955), 202-207.

116. A simple proof of Dirichlet principle. J. Math. Soc. Japan 7 (1955), 67-75.

117. On a positive harmonic function in a half-plane. J. Math. Soc. Japan 7 (1955) 76-78.

118. Functions of $U$-class and its applications. J. Math Soc. Japan 7 (1955), 166-176.

119. Hopf's ergodic theorem on Fuchsian groups. J. Math. Soc. Japan 7 (1955), 276-289.

120. Borel's directions of a meromorphic function in a unit circle. J. Math. Soc. Japan 7 (1955), 290-311.

121. Canonical products for a meromorphic function in a unit circle. J. Math. Soc. Japan 8 (1956), 7-21.

122. Littlewood's theorem on subharmonic functions in a unit circle. Comm. Math. Univ. St. Paul 5 (1956), 3-16.

123. Analogue of Blichfeldt's theorem for Fuchsian groups. Comm. Math. Univ. St. Paul 5 (1956), 17-24.

124. On the modulii of closed Riemann surfaces. Comm. Math. Univ. St. Paul 5 (1956), 25-28.

125. A simple proof of Bieberbach-Grunsky's theorem. Comm. Math. Univ. St. Paul 5 (1956), 29-32.

126. A simple proof of a theorem Erdos and Gillis on the transfinite diameter. Comm. Math. Univ. St. Paul 5 (1956), 115-121.

127. Solution of Neumann's problem without use of integral equations. Comm. Math. Univ. St. Paul 5 (1956), 123-127.

128. On a non-regative subharmonic function in a half-plane. Kōdai Math. Sem. Rep. 8 (1956), 134-141.

129. On a Riemann surface, which is conformally equivalent to a Riemann surface with a finite spherical area. Comm. Math. Univ. St. Paul 6 (1957), 1-8.

130. On Abelian and Schottkyan covering surfaces of a closed Riemann surface. Comm. Math. Univ. St. Paul 6 (1957), 9-27.

131. On a theorem of Fenchel on the total curvature of a closed curve. Comm. Math. Univ. St. Paul 6 (1957), 29-32.

132. On Hardy-Littlewood's maximal theorem. Comm. Math. Univ. St. Paul 6 (1957), $3 i-47$.

133. On the capacity of a set in the space of regular functions and its applications. Comm. Math. Univ. St. Paul 7 (1959), 1-12.

134. Huber's theorem on analytical mappings of a ring domain in a ring domain. Comm. Math. Univ. St. Paul 8 (1960), 41-43.

135. Behnke-Stein's theorem on the existence of a basic differential on a compact Riemann surface with boundary curves. Comm. Math. Univ. St. Paul 8 (1960), 45-51.

136. A theorem on the boundary behaviour of a function in $|z|<1$. Comm. Math. Univ. St. Paul 8 (1960), 53-55.

137. (with S. Shimada). Some metrical theorems on Fuchsian groups. Comm. Math. Univ. St. Paul 8 (1960), 57-62.

138. (with S. Shimada). On a Fuchsian group whose fundamental domain contains no circular arc of $|z|=1$ on its boundary. Comm. Math. Univ. St. Paul 8 (1960), 77-79. 